\title{
The Impact of Biologics and Tofacitinib on Cardiovascular Risk Factors and Outcomes in Patients with Rheumatic Disease: A Systematic Literature Review
}

\author{
Michael Nurmohamed ${ }^{1} \cdot$ Ernest $\mathrm{Choy}^{2} \cdot$ Sadiq Lula ${ }^{3,7} \cdot$ Blerina Kola $^{4} \cdot$ \\ Ryan DeMasi ${ }^{5} \cdot$ Paola Accossato $^{6}$
}

Published online: 9 January 2018

(c) The Author(s) 2018. This article is an open access publication

\begin{abstract}
Introduction Rheumatic diseases are autoimmune, inflammatory diseases often associated with cardiovascular (CV) disease, a major cause of mortality in these patients. In recent years, treatment with biologic and targeted synthetic disease-modifying anti-rheumatic drugs (DMARDs), either as monotherapy or in combination with other drugs, have become the standard of treatment. In this systematic literature review, we evaluated the effect of treatment with biologic or tofacitinib on the $\mathrm{CV}$ risk and outcomes in these patients.

Methods A systematic search was performed in MEDLINE, Embase, the Cochrane Central Register of Controlled Trials, and Cochrane Database of Systematic Reviews for articles reporting on CV risk and events in
\end{abstract}

Sadiq Lula: IMS Health, At the time the work was done.

Electronic supplementary material The online version of this article (https://doi.org/10.1007/s40264-017-0628-9) contains supplementary material, which is available to authorized users.

Michael Nurmohamed

m.nurmohamed@reade.nl

1 Department of Rheumatology, Reade, VU University Medical Center, 3A50, Amsterdam Rheumatology and Immunology Center, Dr. Jan van Breemenstraat 2, 1056 AB Amsterdam, The Netherlands

2 Cardiff University School of Medicine, Cardiff, Wales, UK

3 Envision Pharma Group, London, UK

4 Pfizer, Tadworth, Surrey, UK

5 Pfizer, Collegeville, PA, USA

6 Pfizer, Rome, Italy

7 Present Address: IQVIA, London, UK patients with rheumatic disease treated with a biologic agent or tofacitinib. Articles identified were subjected to two levels of screening. Articles that passed the first level based on title and abstract were assessed on full-text evaluation. The quality of randomized clinical trials was assessed by Jadad scoring system and the quality of the other studies and abstracts was assessed using the Downs and Black instrument. The data extracted included study design, baseline patient characteristics, and measurements of $\mathrm{CV}$ risk and events.

Results Of the 5722 articles identified in the initial search, screening yielded 105 unique publications from 90 unique studies (33 clinical trials, 39 prospective cohort studies, and an additional 18 retrospective studies) that reported $\mathrm{CV}$ risk outcomes. A risk of bias analysis for each type of report indicated that they were of good or excellent quality. Importantly, despite some limitations in data reported, there were no indications of significant increase in adverse $\mathrm{CV}$ events or risk in response to treatment with the agents evaluated.

Conclusions Treatment with biologic or tofacitinib appears to be well-tolerated with respect to $\mathrm{CV}$ outcomes in these patients. 


\section{Key Points}

This systematic literature review evaluated 105 publications from 90 unique studies reporting cardiovascular (CV) outcomes in response to treatment with biologic or targeted synthetic diseasemodifying anti-rheumatic drugs (DMARDs).

There were no indications of significant increase in adverse $\mathrm{CV}$ events in response to treatment with the agents evaluated.

Treatment with biologic or targeted synthetic DMARDs appears to be well-tolerated with respect to $\mathrm{CV}$ outcomes by these patients.

The conclusions in this review need to be interpreted with caution as quality and quantity of data vary substantially between the various drugs included, thereby limiting stringent comparisons.

\section{Introduction}

Rheumatic diseases are systemic, autoimmune, inflammatory diseases characterized by chronic severe pain and progressive swelling and destruction of joints resulting in functional impairment, disability, reduced quality of life, and even death [1]. Rheumatic diseases are often associated with other co-morbidities, the most common of which is cardiovascular (CV) disease (CVD), a major cause for mortality in these patients $[2,3]$. Clinical disease activity and systemic inflammation, as evidenced by increase in specific biomarkers such as C-reactive protein (CRP) and erythrocyte sedimentation rate (ESR), are strong predictors of increased risk of CVD [2-5], subsequent development of CVD [6, 7], and CVD-related death [2, 3, 8]. A recently published meta-analysis showed that the relative risk for myocardial infarction (MI) was significantly increased in patients with rheumatoid arthritis (RA) and psoriatic arthritis (PsA) [9].

Over the last decade, biologic disease-modifying antirheumatic drugs (bDMARDs), most notably tumor necrosis factor inhibitors (TNFi), and more recently, targeted synthetic disease-modifying anti-rheumatic drugs (tsDMARDs), either as monotherapy or in combination with other drugs, have become the standard of treatment for most rheumatic diseases $[10,11]$. The drugs included in this review have been approved for the treatment of RA (abatacept, adalimumab, certolizumab pegol, etanercept, golimumab, infliximab, rituximab, tocilizumab, and tofacitinib), PsA (abatacept, adalimumab, certolizumab pegol, etanercept, golimumab, infliximab, secukinumab, and ustekinumab), ankylosing spondylitis (AS; adalimumab, certolizumab pegol, etanercept, golimumab, infliximab, and secukinumab), and juvenile idiopathic arthritis (JIA; abatacept, adalimumab, etanercept, and tocilizumab). These medications have been key to reducing disease activity and improving patient quality of life $[10,11]$. However, their impact on the risk for CVD, the primary driver of mortality in these patients, is still unclear and needs to be evaluated given the increasingly widespread use of these agents. In particular, the reports of effects on lipid profiles need to be assessed with respect to effect on risk for CVD.

The overall objectives of this systematic literature review were to assess and compare the effect of the different agents on $\mathrm{CV}$ events or risk outcomes and to assess differences in these outcomes according to patient and disease type.

\section{Methods}

A systematic literature review was performed according to Preferred Reporting Items for Systematic Reviews and Meta-Analyses (PRISMA) statement [12] to identify studies that investigated CV risks or events in patients with rheumatic diseases treated with bDMARDs or tsDMARDs approved for the treatment of rheumatic diseases, prescribed either as stand-alone therapy or in combination.

\subsection{Data Sources and Searches}

The data sources searched included MEDLINE, Embase, the Cochrane Central Register of Controlled Trials, and the Cochrane Database of Systematic Reviews. Databases were searched using specific search strings, which included synonyms and combinations of the following key terms: RA, JIA, PsA, AS, adalimumab, etanercept, infliximab, certolizumab, golimumab, tofacitinib, methotrexate, DMARDs, biosimilars, and CV risk factors or outcomes. The full search strings used for the electronic databases and conference proceedings, including all the search terms and the relationships between the search terms, are listed in Electronic Supplementary Material \#1. Additional studies were identified from previously published systematic literature reviews or from the references of included studies. Searches were restricted to English language and limited to the timeframe of January 2000 to December 2015. 


\subsection{Study Selection}

All randomized and non-randomized control trials and observational studies on adult patients diagnosed with RA, AS, PsA, and patients of any age diagnosed with JIA were included. Preclinical (animal) or studies that pooled data from different agents, case reports, case series, case studies, previously published systematic literature reviews, letters, commentaries, and editorials were excluded. Also excluded were studies that examined the effect of bDMARDs and tsDMARDs on CV risk and events but provided insufficient data to interpret findings, studies with a sample size of fewer than 30 patients, and studies assessing novel CV biomarkers not in routine clinical use.

\subsection{Screening}

Two levels of screening were performed. In level I, studies were identified based on title and abstract by SL, eliminating all publications with duplication of study populations. Carole Jones performed a quality check of $10 \%$ of all screened studies. Discrepancy $\geq 5 \%$ would have prompted a re-evaluation of the whole dataset. All authors reviewed all studies that were eligible for level II screening. In level II, qualifying articles identified in level I were assessed based on the full-text by following a standard hierarchy of evidence. Publications not meeting the inclusion criteria were excluded. Carole Jones screened $20 \%$ of the publications excluded at the level II screening stage and also reviewed all publications determined to be eligible for inclusion. All disagreements were resolved by consensus.

\subsection{Data Extracted}

For each publication, the data were extracted by SL and reviewed by all authors. The information extracted included study design, baseline patient characteristics, $\mathrm{CV}$ risk profile, $\mathrm{CV}$ risk factors, $\mathrm{CV}$ events, and other observations, including CRP levels and lipid levels, where available, reported in patients with rheumatic diseases treated with bDMARDs or tsDMARDs. Blood lipid levels included total cholesterol (TC), low-density lipoprotein cholesterol (LDL-C), high-density lipoprotein cholesterol (HDL-C), triglycerides (TG), apolipoprotein A1 (Apo-A1), apolipoprotein B (Apo-B), and atherogenic index (ratio of TC to HDL). CV events extracted included MI, stroke, venous thrombotic events (VTEs), heart failure (HF), pulmonary thromboembolism, and hypertension. Traditional, novel, and disease-specific CV risk factors or markers of atherosclerosis used in disease diagnosis included augmentation index (AIx), AIx normalized for a heart rate of
75 beats/min (AIx@75), cardio-ankle vascular index (CAVI), carotid intima-media thickness (cIMT), pulse wave velocity (PWV), systolic and diastolic blood pressure (BP), arterial stiffness, and $\mathrm{N}$-terminal pro-brain natriuretic peptide (NT-proBNP). CV risk scores included the Reynolds, Systematic COronary Risk Evaluation (SCORE), and Framingham risk scores. All CV-related mortality was also extracted.

\subsection{Risk of Bias}

The quality of randomized controlled trials (RCTs) was assessed using recommendations from the National Institute for Health and Clinical Excellence (NICE) single technology appraisal (STA) manufacturer's template. RCTs were evaluated using the Jadad scoring system [13], which ranges from 0 (very poor study) to 5 (rigorous study). The quality of all non-RCTs (nRCTs) and observational studies were assessed using the Downs and Black instrument [14], which consists of a checklist of 27 items; the score can range from 0 (very poor study) to 32 (rigorous study). Abstracts from conference proceedings were assessed using the modified-Downs and Black instrument [15], which also consists of a checklist of 27 items; however, the score ranges from 0 (very poor study) to 28 (rigorous study).

\section{Results}

\subsection{Search}

The searches of the various databases yielded 5722 articles, of which 5123 were unique (Fig. 1). After the level I screening of title and abstracts, 344 articles met the inclusion criteria and 4779 articles were excluded. Level II screening of these articles based on full-text analysis yielded 196 relevant articles, with 148 being excluded for various criteria (Fig. 1). A deeper analysis of these showed that 41 articles had insufficient $\mathrm{CV}$ data to interpret findings, 26 articles reported on novel $\mathrm{CV}$ biomarkers that were not used in routine clinical practice, and 24 articles had enrolled $<30$ patients in the studies, leaving 105 unique publications reporting results from 95 studies.

\subsection{Risk of Bias Analysis}

The mean Jadad score for the 22 RCTs with full publications was 3.9, with $19(86.4 \%)$ studies being of good quality. Of the 22 studies, 13 (59.1\%) scored excellent with a mean Jadad score of 4.6, and six (27.3\%) scored good 


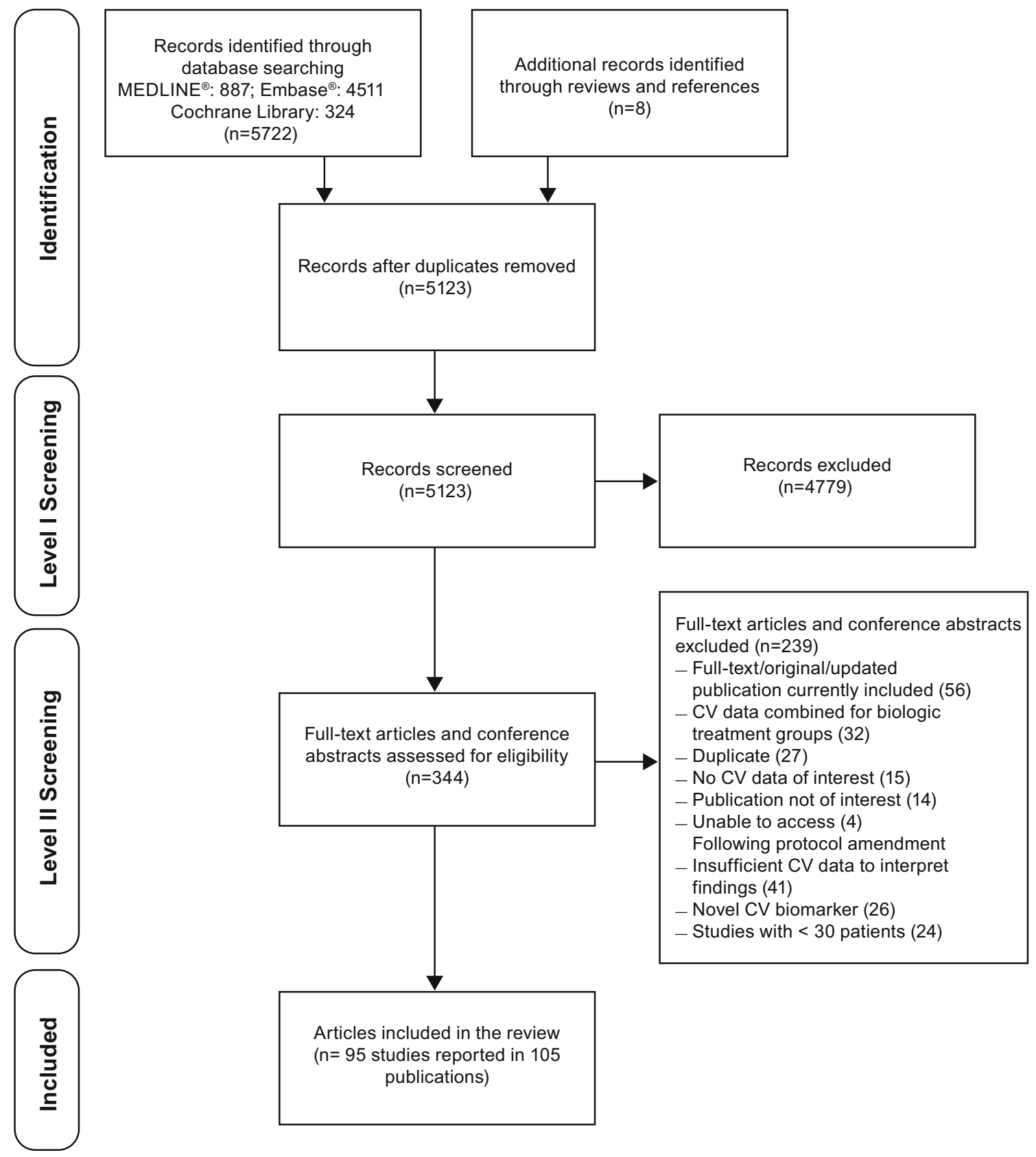

Fig. 1 Preferred Reporting Items for Systematic Reviews and Meta-Analyses (PRISMA) flow diagram. Level I = studies identified based on title and abstract; level II = articles identified in level I assessed based on full-text analysis. $C V$ cardiovascular

with a mean Jadad score of 3.2 ; three $(13.6 \%)$ studies scored poor with a mean Jadad score of 2.0. The mean Downs and Black quality assessment score for the 44 nRCTs with full publications was 15.5 , with $98 \%$ of the studies being good or excellent quality. The mean modified Downs and Black quality assessment score for the 24 abstracts from conference proceedings was 5.5, with $75 \%$ of the published abstracts being of good quality.

\subsection{Cardiovascular (CV) Risk in Rheumatoid Arthritis}

\subsubsection{Study Characteristics}

The characteristics of all the studies classified by type for all therapeutic agents are given in Electronic Supplementary Material \#2 Table 1 . There were a total of 25 RCTs, 32 prospective cohort (PC) studies, and 16 retrospective cohort (RC) studies on the CV risk in RA. The number of 
Table 1 Summary of cardiovascular risk assessment for patients with rheumatoid arthritis

\begin{tabular}{|c|c|c|c|c|c|c|c|c|c|}
\hline \multirow[t]{2}{*}{ Risk factor } & \multicolumn{8}{|c|}{ boDMARD } & \multirow{2}{*}{$\begin{array}{l}\text { tsDMARD } \\
\text { TOFA }\end{array}$} \\
\hline & $\mathrm{ABA}$ & ADA & ETN & GLM & INF & RTX & SEC & $\mathrm{TCZ}$ & \\
\hline $\mathrm{TC}$ & $\leftrightarrow$ & $\leftrightarrow$ & $\uparrow$ & & $\uparrow$ & $\uparrow / \leftrightarrow$ & $\leftrightarrow$ & $\uparrow$ & $\uparrow$ \\
\hline HDL-C & $\uparrow / \leftrightarrow$ & $\uparrow / \leftrightarrow$ & $\uparrow$ & & $\uparrow$ & $\uparrow / \leftrightarrow$ & $\leftrightarrow$ & $\uparrow$ & $\uparrow$ \\
\hline LDL-C & $\uparrow / \leftrightarrow$ & $\uparrow / \leftrightarrow$ & $\leftrightarrow$ & & $\uparrow / \leftrightarrow$ & $\leftrightarrow$ & $\leftrightarrow$ & $\uparrow$ & $\uparrow$ \\
\hline TG & $\leftrightarrow$ & $\leftrightarrow$ & $\leftrightarrow$ & & $\uparrow$ & $\leftrightarrow$ & & $\uparrow$ & $\uparrow$ \\
\hline Atherogenic index & $\leftrightarrow$ & $\leftrightarrow$ & & & $\uparrow / \leftrightarrow / \downarrow$ & $\uparrow / \leftrightarrow$ & $\leftrightarrow$ & $\downarrow$ & $\leftrightarrow$ \\
\hline ApoB:ApoA-1 & & $\leftrightarrow$ & $\downarrow$ & & & & $\leftrightarrow$ & $\downarrow$ & $\leftrightarrow$ \\
\hline Systolic BP & $\leftrightarrow$ & $\leftrightarrow$ & $\leftrightarrow$ & & $\leftrightarrow$ & $\leftrightarrow$ & & $\leftrightarrow$ & \\
\hline Diastolic BP & $\leftrightarrow$ & $\leftrightarrow$ & & & $\leftrightarrow$ & & & & \\
\hline CAVI & $\leftrightarrow$ & $\downarrow$ & $\downarrow$ & & & & & $\downarrow$ & \\
\hline Augmentation index & $\leftrightarrow$ & $\downarrow$ & $\downarrow$ & & $\uparrow / \leftrightarrow$ & $\leftrightarrow$ & & $\downarrow$ & \\
\hline cIMT & $\leftrightarrow$ & $\leftrightarrow$ & & & $\leftrightarrow$ & $\downarrow$ & & $\leftrightarrow$ & \\
\hline CRP & $\downarrow / \leftrightarrow$ & $\downarrow$ & $\downarrow$ & & $\downarrow$ & $\downarrow / \leftrightarrow$ & & $\downarrow$ & $\downarrow$ \\
\hline sPLA2 & & $\downarrow$ & & & & & & $\downarrow$ & \\
\hline SAA & & $\downarrow$ & & & & & & $\downarrow$ & \\
\hline MI & & $0.3-0.6 \%$ & $0.8 \%$ & & $0.2 \%$ & & & $0.6 \%$ & \\
\hline Stroke & & $0.3 \%$ & & & & & & $0.3 \%$ & \\
\hline Carotid artery plaque & $\leftrightarrow$ & & & & & & & $\leftrightarrow$ & \\
\hline FMD & & $\uparrow$ & & & & & & & \\
\hline Rate of CV SAEs per $100 \mathrm{PY}$ & & & & $0.25-0.43$ & & & & & \\
\hline Adjusted $\mathrm{HR}^{\mathrm{a}}$ & $1.0-1.6$ & $0.8-1.8$ & 1.8 & & $1.1-1.3$ & $0.98-2.4$ & & 0.37 & \\
\hline
\end{tabular}

Blank cells indicate that data were not reported in original publications

$A B A$ abatacept, $A D A$ adalimumab, Apo apolipoprotein, boDMARD biological originator disease-modifying anti-rheumatic drug, $B P$ blood pressure, $C A V I$ cardio-ankle vascular index, $C I M T$ carotid inter-media thickness, $C R P$ C-reactive protein, $C V$ cardiovascular, ETN etanercept, $F M D$ flow-mediated dilation, $G L M$ golimumab, $H D L-C$ high-density lipoprotein cholesterol, $H R$ hazard ratio, $I N F$ infliximab, $L D L-C$ lowdensity lipoprotein cholesterol, $M I$ myocardial infarction, $P Y$ person-years, $R T X$ rituximab, $S A A$ serum amyloid A, $S A E$ serious adverse event, $S E C$ secukinumab, $s P L A 2$ secretory phospholipase $\mathrm{A}_{2}, T C$ total cholesterol, TCZ tocilizumab, TG triglycerides, TOFA tofacitinib, $t s D M A R D$ targeted synthetic disease-modifying anti-rheumatic drug, $\uparrow$ significantly increased, $\downarrow$ significantly decreased, $\leftrightarrow$ no significant effect

${ }^{\text {a }}$ Relative to the comparator in that study

patients enrolled in these studies ranged from 30 to 68,447 . Treatment duration depended on the therapeutic agent being evaluated and ranged from 6 to 624 weeks.

\subsubsection{Patient Characteristics}

The characteristics of all RA patients enrolled in these studies for all therapeutic agents evaluated are summarized in Electronic Supplementary Material \#2 Table 2. Briefly, all patients enrolled in these studies were adults (range $38.0-62.7$ years), mostly female (range $40.8-100 \%$ ), and had moderate to severe disease with disease duration ranging from 0.3 to 17.6 years.

\subsubsection{Risk Analysis}

The results of CV risk analysis for all therapeutic agents are summarized in Table 1. Overall, in patients with RA there is a higher prevalence of HF, increased incidence of impaired myocardial and longitudinal deformation, and increased left ventricle circumferential apical strain. The findings for each drug are given in brief here.

3.3.3.1 Abatacept Data on patients with RA treated with abatacept were obtained from one RCT (conference abstract) [16], one PC study (full-length article [17] and conference abstract [18]), and six RC studies (all conference abstracts) [19-25]. There were no changes from baseline reported for TC $[16,17,21,23,25]$ and TG [17, 21, 23, 25]. Saito et al. [24] reported increase in both 
HDL-C and LDL-C, but two other studies reported no significant change $[17,21,23,25]$. There was no significant effect on BP [17], atherogenic index [16], AIx [16-18, 21, 23, 25], CAVI [18], cIMT [16], and carotid artery plaques [16]. Kume et al. [16] reported significant reduction in CRP, but Provan et al. [17] reported that there was no effect. For patients with RA treated with abatacept, the rate of $\mathrm{CV}$ events was estimated at 3.3 per 100 patientyears (PY) [19] and the hazard ratio (HR) range was $1.0-1.6$ relative to the comparator drug after adjusting for potential confounding factors $[19,20]$. The Framingham 10-year CVD risk was significantly reduced from 12.7 to $10.6(p=0.011)[22]$ and the adjusted Reynolds risk score was $0.4[21,23,25]$.

3.3.3.2 Adalimumab Data on patients with RA treated with adalimumab were obtained from five RCTs (four fulllength articles [26-29] and three conference abstracts [30-32]), five PC studies (four full-length articles [33-36] and one conference abstract [37]), and six RC studies (four full-length articles [38-41] and two conference abstracts $[19,24])$. There was no effect on TC $[27,33,36,40]$ or TG $[33,36,40]$. In some studies there were significant increases in HDL-C [24, 26, 29, 32] and LDL-C $[24,26,32]$, but there were others that reported no significant change in these lipids $[33,36,40]$. There was significant reduction in CRP [27, 33, 36], AIx [27, 30], CAVI [27, 30], serum amyloid A (SAA) [26, 32], secretory phospholipase $\mathrm{A}_{2}$ (sPLA2) [26, 32], and arterial stiffness [30]. There were no significant effects on cIMT [27, 36], BP [34, 36], ApoB:ApoA-1 ratio [33], or atherogenic index $[27,30]$. The rate for MI was $0.3-0.6 \%$ and for stroke was $0.3 \%$. The rate of CV events was 2.7 per $100 \mathrm{PY}$ [19] and the rate of VTEs was 0.3 per 100 PY [35]. The rate of thromboembolic events was greater in patients who developed anti-adalimumab antibodies (ADAb) at 2.7 per 100 PY compared with 0.8 per $100 \mathrm{PY}$ for patients who did not develop ADAb [39]. The HR range was 0.8-1.8 relative to rituximab or non-biological disease-modifying antirheumatic drugs (nbDMARDs) after adjusting for potential confounding factors $[19,35]$.

3.3.3.3 Certolizumab Pegol Standard CV risk outcomes were not reported in two full-length publications from a single RCT and its long-term extension on patients with RA treated with certolizumab pegol $[42,43]$. However, the prevalence of hypertension was estimated to be $8.2-10.2 \%$. The total of 11 deaths, six occurring in the first 12 months and five in the second 12 months, corresponded to a rate of 0.73 per $100 \mathrm{PY}$. None of the deaths were considered related to treatment with certolizumab pegol.
3.3.3.4 Etanercept Data on patients with RA treated with etanercept were obtained from three RCTs (two full-length articles [27, 44] and one conference abstract [30]), five PCs (all full-length articles) [35, 45-48], and five RCs (four full-length articles [38, 49-51] and two conference abstracts [19, 52]). Treatment with etanercept increased HDL-C $[45,47,48]$ but had no significant effect on LDL-C or TG $[45,47]$. Etanercept had a favorable effect on lipid profile based on a significantly lower ApoB:ApoA-1 ratio, but primarily in patients exhibiting good or moderate response [47] according to the European League Against Rheumatism (EULAR) criteria [11]; however, TC was increased significantly in these patients, whereas there was no statistical difference in EULAR non-responders or in other studies [27, 48]. Arterial stiffness [30], AIx [27, 30, 45, 46], Disease Activity Score-28 (DAS28) [45], CAVI [27, 30], CRP [27, 45, 46, 48], and left ventricle mass index [45] were reduced significantly in patients treated with etanercept. Small increases in CV-associated serious adverse events (SAEs) such as HF, coronary artery disease, MI, and cerebrovascular events were reported in patients with diabetes mellitus and/or chronic pulmonary disease as co-morbidities [44]. Overall, there was a reduced risk of HF in patients treated with etanercept $[49,51]$, and the rates of $\mathrm{CV}$ events and serious $\mathrm{CV}$ events were 3.0 per $100 \mathrm{PY}$ [19] and 1.0 per $100 \mathrm{PY}[50,52]$, respectively. The risk of first VTE was 0.3 per $100 \mathrm{PY}$ and the adjusted HR was 1.8 relative to nbDMARDs [35].

3.3.3.5 Golimumab There is sparse information on the effect of golimumab treatment on CV events. What is available was reported in a conference abstract on data obtained from five clinical trials [53]. The rates of CV SAEs and ischemic CV events were reported at 0.25 per 100 PY and 0.43 per 100 PY, respectively.

3.3.3.6 Infliximab Data on patients with RA treated with infliximab were obtained from four RCTs (three full-length articles [54-56] and two conference abstracts [57, 58]), 11 PCs (11 full-length articles [35, 59-68] and one conference abstract [69]), and five RCs (four full-length articles [38, 49, 51, 70] and one conference abstract [19]). Data from several studies showed that treatment with infliximab resulted in significant increase in TC [54, 57-63, 65, 67, 68, 70], HDL-C [57-65], and TG $[61,63,65,70]$. Results with LDL-C and atherogenic index were mixed. In three PC studies, there was significant increase in LDL-C for at least the first 12 weeks $[60,61,64]$, whereas data from two RCTs $[54,57,58]$ and two PC studies $[65,67,68]$ showed no significant change. Significant improvement in atherogenic index was reported in one RCT [57, 58], but significant worsening was reported in three PC studies [61, 63, 65], and no significant 
change was reported in one RCT [56] and two PC studies $[59,60]$. Several studies reported significant reduction in inflammation as determined by decreased CRP levels [56, 60, 64, 67, 68, 70]. In one RCT [55], AIx worsened in response to infliximab treatment but showed no significant change in another [56]. Treatment with infliximab resulted in higher aortic stiffness index, aortic strain, and aortic distensibility [69], but a lower risk of HF [51], decreased arterial stiffness as indicated by decreased PWV [56], and decreased aortic beta index [69]. There were no changes reported in BP and cIMT. Long-term treatment may improve myocardial deformation and normalize left-ventricular torsion [67, 68]. Insulin resistance [57, 58], Homeostatic Model Assessment of Insulin Resistance (HOMA-IR) [57, 58], and aortic elasticity [69] all improved with infliximab treatment. There was no significant change in NT-proBNP [57, 58, 63]. SAEs were reported in $68.2 \%$ of patients who experienced CVD-related mortality [66]. The rates of CV events and VTEs were 2.1 per $100 \mathrm{PY}$ [19] and 0.5 per $100 \mathrm{PY}$ [35], respectively. The adjusted HR for $\mathrm{CV}$ events was 1.1-1.3 relative to rituximab or nbDMARDs [19, 35].

3.3.3.7 Rituximab Data on patients with RA treated with rituximab were obtained from six PC studies (four fulllength articles [17, 71-73] and two conference abstracts $[74,75]$ ) and four RC studies (two full-length articles $[28,76]$ and six conference abstracts $[19-21,23,25,31])$. There was no significant effect on LDL-C [17, 21, 23, 25, 71-74], TG [17, 71-74], AIx [17, 71, 72], PWV [17], or systolic BP [17]. Significant increases in TC and HDL-C, and a decrease in atherogenic index, were reported in two PC studies [71, 74], and no significant change was reported in three PC studies [17, 72, 73] and one RC study [21, 23, 25]. Significant decrease in CRP was reported in two PC studies [71, 74], whereas no significant change was reported in another [17]. In addition, there were significant decreases in ESR and DAS28 [74]. The rate of MI, the most common cardiac adverse event (AE) $[28,31,76]$, was $0.39-0.6$ per $100 \mathrm{PY}[28,31,75,76]$, and similar to that in the general RA population $(0.48-0.59$ per $100 \mathrm{PY})[28,31,76]$. The overall rate of $\mathrm{CV}$ events was 2.4 per $100 \mathrm{PY}$. However, there were more CV-related deaths among patients treated with rituximab than those treated with placebo for over 11 years $[28,31,76]$. The rates of stroke, pulmonary embolism, deep vein thrombosis, and death per $100 \mathrm{PY}$ were $0.5,0.3,0.4$, and 1.6 , respectively [75]. The adjusted HR for CV events was 1.0 relative to abatacept $[19,20]$ and the adjusted Reynolds risk score was $0.1[21,23,25]$.

3.3.3.8 Secukinumab In the two conference abstracts from a single RCT on secukinumab [77, 78], there were no significant changes in TC, HDL-C, LDL-C, atherogenic index, ApoB:ApoA-1 ratio, and no CV events reported.

3.3.3.9 Tocilizumab Data on patients with RA treated with tocilizumab were obtained from ten RCTs (seven full-length articles [26, 27, 79-83] and five conference abstracts $[16,30,32,84,85]$ ), seven PC studies (six full-length articles $[17,37,72,86-88]$ and one conference abstract [89]), and six RC studies (one full-length article [90] and seven conference abstracts [20-25, 91]). Most studies reported significant increases in TC [16, 21, 23, 25, 27, 79-81, 83-86, 90, 91], HDL-C $\quad[22, \quad 24, \quad 26, \quad 32, \quad 79, \quad 85, \quad 92], \quad$ LDL-C [21, 23-26, 32, 81, 85, 92], and TG [21, 23, 25, 79, 86, 92], although two PC studies reported no significant change from baseline [17, 72] and one RCT reported that the increase in TC was reversible [79]. When measured, there was significant reduction in CRP levels [16, 17, 27, 80, 84, 90], CAVI $[16,27,30]$, atherogenic index [79], AIx [16, 22, 27, 30], and Framingham 10-year CVD risk [22]. There were no changes reported in cIMT [16, 27] or BP [17]. Compared with patients treated with methotrexate, hypertension and vascular disorders were more common in patients treated with tocilizumab [81]. The rates per $100 \mathrm{PY}$ of serious cardiac dysfunction, $\mathrm{HF}$, ischemic heart disease, $\mathrm{MI}$, angina pectoris, stroke, and death were $1.11,0.47,0.43,0.09-0.2,0.16,0.15$, and 0.07 , respectively [88]. The rates of cardiac AEs and CVrelated death were $0.4 \%[80,84]$ and $6.7-9.0 \%[80,84,88]$, respectively, both higher than the rates for patients receiving placebo ( 0.2 and $5.1 \%$, respectively) [80, 84]. In addition, the rate of cerebrovascular-related deaths in tocilizumab-treated patients was 5.6\% [88]. The proportion of patients with serious cardiac dysfunction did not increase over time with treatment [88]. The adjusted HR was 0.4 [87].

3.3.3.10 Tofacitinib Data on patients with RA treated with tofacitinib were obtained from nine RCTs (nine fulllength articles [29, 83, 93-99] and two conference abstracts $[100,101])$. Most studies reported significant increases in TC [83, 93, 95, 98, 99], HDL-C [29, 83, 93-101], LDL-C [29, 83, 93-101], and TG [83, 97, 100, 101], and a significant decrease in CRP $[95,97,100,101]$. Treatment with statin can normalize cholesterol levels. There were no changes in atherogenic index [83, 93] and BP [95].

\subsection{Risk in Psoriatic Arthritis}

\subsubsection{Study Characteristics}

The characteristics of all studies classified by type for all therapeutic agents are given in Electronic Supplementary Material \#2 Table 3. There were a total of three RCTs [102-105], two PC studies [62, 106], and two RC studies $[41,107]$ on the CV risk in PsA. The number of patients 
enrolled in these studies ranged from 60 to 23,458 . Treatment duration depended on the therapeutic agent being evaluated and ranged from 24 to 624 weeks.

\subsubsection{Patient Characteristics}

The characteristics of all PsA patients enrolled in these studies for all therapeutic agents evaluated are summarized in Electronic Supplementary Material \#2 Table 4. Briefly, all patients enrolled in these studies were adults (range 42.5-49.6 years), the proportion of female patients ranged from 29.8 to $60.0 \%$, and the disease duration ranged from 0.9 to 14.6 years.

\subsubsection{Risk Analysis}

Overall, all PsA patients have higher prevalence of CV comorbidities, including diabetes and hypertension, than the general population [105]. Furthermore, women have higher $\mathrm{CV}$ risk than men due to a higher prevalence of metabolic syndrome and elevated BP [105]. There were no studies reporting $\mathrm{CV}$ events or biomarkers for patients with PsA treated with abatacept, certolizumab pegol, golimumab, rituximab, tocilizumab, or tofacitinib. The results of $\mathrm{CV}$ risk analysis for all therapeutic agents are summarized in Table 2.

3.4.3.1 Adalimumab Data on patients with PsA treated with adalimumab were obtained from two RC studies, both full-length articles [41, 107]. Costa et al. [107] reported that HDL-C was increased and TG was decreased. Burmester et al. [41] reported that the rate of CHF per $100 \mathrm{PY}$ was zero.
3.4.3.2 Etanercept Data on patients with PsA treated with etanercept were obtained from one full-length article on a retrospective analysis of data from an RCT [105], one PC study (conference abstract) [106], and one full-length article for a RC study [107]. There was a significant increase in HDL-C [105, 107], although the PC study reported no change [106]. There was significant reduction in CRP [105, 106]. Costa et al. [107] reported decrease in TG, but the other two studies reported no significant change $[105,106]$. There were no significant effects on TC [105], LDL-C [105, 106], atherogenic index [106], or ApoB:ApoA-1 ratio [105, 106]. However, the favorable CV effects could not be attributed to the lipid profile [106].

3.4.3.3 Infliximab In the single PC study evaluating the effect of infliximab treatment on $\mathrm{CV}$ risk factors in patients with PsA [62], there was a sustained increase in TC and HDL-C but no significant effect on LDL-C or TG. There was also a significant decrease in atherogenic index and CRP levels.

3.4.3.4 Secukinumab Among PsA patients treated with secukinumab, the reported incidence rate for major cardiac AEs was 0.7 per 100 PY based on data from a single clinical trial [103, 104]. No other CV-related events or biomarkers were reported.

3.4.3.5 Ustekinumab In patients treated with ustekinumab for PsA, as reported in a conference abstract on a single clinical trial [102], the rate of major CV AEs was 0.7 per 100 PY. No other CV-related events or biomarkers were reported.
Table 2 Summary of cardiovascular risk assessment for patients with psoriatic arthritis

\begin{tabular}{|c|c|c|c|c|c|}
\hline \multirow[t]{2}{*}{ Risk factor } & \multicolumn{5}{|c|}{ boDMARD } \\
\hline & ADA & ETN & INF & SEC & UST \\
\hline $\mathrm{TC}$ & & $\leftrightarrow$ & $\uparrow$ & & \\
\hline HDL-C & $\uparrow$ & $\uparrow / \leftrightarrow$ & $\uparrow$ & & \\
\hline LDL-C & & $\leftrightarrow$ & $\leftrightarrow$ & & \\
\hline TG & $\downarrow$ & $\downarrow / \leftrightarrow$ & $\leftrightarrow$ & & \\
\hline Atherogenic index & & $\leftrightarrow$ & $\downarrow$ & & \\
\hline ApoB:ApoA-1 & & $\leftrightarrow$ & & & \\
\hline CRP & & $\downarrow$ & $\downarrow$ & & \\
\hline Rate of major CV AEs, per $100 \mathrm{PY}$ & & & & 0.7 & 0.66 \\
\hline
\end{tabular}

Blank cells indicate that data were not reported in original publications

$A D A$ adalimumab, $A E$ adverse event, Apo apolipoprotein, boDMARD biological originator disease-modifying anti-rheumatic drug, $C R P$ C-reactive protein, $C V$ cardiovascular, $E T N$ etanercept, $H D L-C$ highdensity lipoprotein cholesterol, $I N F$ infliximab, $L D L-C$ low-density lipoprotein cholesterol, $P Y$ personyears, SEC secukinumab, TC total cholesterol, $T G$ triglycerides, UST ustekinumab, $\uparrow$ significantly increased, $\downarrow$ significantly decreased, $\leftrightarrow$ no significant effect 


\subsection{Risk in Ankylosing Spondylitis}

\subsubsection{Study Characteristics}

The characteristics of all the studies classified by type for all therapeutic agents are given in Electronic Supplementary Material \#2 Table 5. There were a total of two RCTs [108-110], eight PC studies [54, 55, 62, 111-115], and one RC study [41] on CV risk in AS. The number of patients enrolled in these studies ranged from 30 to 23,458. Treatment duration depended on the therapeutic agent being evaluated and ranged from 7 to 624 weeks.

\subsubsection{Patient Characteristics}

The characteristics of all AS patients enrolled in these studies for all therapeutic agents evaluated are summarized in Electronic Supplementary Material \#2 Table 6. Briefly, all patients enrolled in these studies were adults (range 34.2-43.1 years), the proportion of female patients ranged from 3.1 to $46.7 \%$, and all patients had moderate to severe disease with a mean Bath Ankylosing Spondylitis Disease Activity Index (BASDAI) ranging from 4.9 to 7.0 and disease duration ranging from 1.5 to 13.0 years.

\subsubsection{Risk Analysis}

The results of CV risk analysis for all therapeutic agents are summarized in Table 3. There were no studies reporting CV events or biomarkers for patients with AS treated with abatacept, certolizumab pegol, rituximab, tocilizumab, ustekinumab, or tofacitinib.

3.5.3.1 Adalimumab In a full-length article on a RC study on patients treated with adalimumab [41], the rate of CHF was reported to be 0.1 per 100 PY. No other CV events were reported.

3.5.3.2 Etanercept Data on patients with AS treated with etanercept were obtained from two PC studies [111, 112], both full-length articles. van Eijk et al. [111] reported that in response to etanercept there was a significant increase in TC, HDL-C, LDL-C, and TG accompanied by a significant decrease in SAA particles in HDL-C, atherogenic index, ApoB:ApoA-1 ratio, and CRP. On the other hand, van Halm et al. [112] reported that in patients treated with etanercept, there were negative correlations between disease parameters and TC, HDL-C, and TG, although there were no significant changes in the levels of these lipids. No other CV events were reported.
Table 3 Summary of cardiovascular risk assessment for patients with ankylosing spondylitis

\begin{tabular}{|c|c|c|c|c|c|}
\hline \multirow[t]{2}{*}{ Risk factor } & \multicolumn{5}{|c|}{ boDMARD } \\
\hline & ADA & ETN & GLM & $\mathrm{INF}$ & SEC \\
\hline TC & & $\uparrow$ & $\uparrow$ & $\uparrow / \leftrightarrow$ & \\
\hline HDL-C & & $\uparrow$ & $\uparrow$ & $\uparrow / \leftrightarrow$ & \\
\hline LDL-C & & $\uparrow$ & $\leftrightarrow$ & $\leftrightarrow$ & \\
\hline TG & & $\uparrow$ & $\uparrow$ & $\uparrow / \leftrightarrow$ & \\
\hline Systolic BP & & & $\leftrightarrow$ & $\downarrow / \leftrightarrow$ & \\
\hline Diastolic BP & & & $\leftrightarrow$ & $\downarrow / \leftrightarrow$ & \\
\hline Atherogenic index & & $\downarrow$ & $\leftrightarrow$ & $\downarrow / \leftrightarrow$ & \\
\hline ApoB:ApoA-1 & & $\downarrow$ & & & \\
\hline Augmentation index & & & $\leftrightarrow$ & $\leftrightarrow$ & \\
\hline cIMT & & & $\leftrightarrow$ & & \\
\hline CRP & & $\downarrow$ & & $\downarrow$ & \\
\hline SAA & & $\downarrow$ & & & \\
\hline CHF per $100 \mathrm{PY}$ & 0.1 & & & & \\
\hline Rate of major CV AEs, per $100 \mathrm{PY}$ & & & & & 0.4 \\
\hline \multicolumn{6}{|c|}{ Blank cells indicate that data were not reported in original publications } \\
\hline \multicolumn{6}{|c|}{$\begin{array}{l}A D A \text { adalimumab, } A E \text { adverse event, } A p o \text { apolipoprotein, } b o D M A R D \text { biological originator disease-modi- } \\
\text { fying anti-rheumatic drug, } B P \text { blood pressure, } C H F \text { congestive heart failure, } c I M T \text { carotid inter-media } \\
\text { thickness, } C R P \text { C-reactive protein, } C V \text { cardiovascular, } E T N \text { etanercept, } G L M \text { golimumab, } H D L-C \text { high- } \\
\text { density lipoprotein cholesterol, } I N F \text { infliximab, } L D L-C \text { low-density lipoprotein cholesterol, } P Y \text { person- } \\
\text { years, } S A A \text { serum amyloid A, } S E C \text { secukinumab, } T C \text { total cholesterol, } T G \text { triglycerides, } \uparrow \text { significantly } \\
\text { increased, } \downarrow \text { significantly decreased, } \leftrightarrow \text { no significant effect }\end{array}$} \\
\hline
\end{tabular}


3.5.3.3 Golimumab Data on patients with AS treated with golimumab were obtained from a single full-length article on an RCT [110]. There were significant increases in TC, HDL-C, and TG, but not in LDL-C. There was also a significant decrease in CRP. There were no significant changes in AIx, BP, cIMT, and PWV. No other CV events were reported.

3.5.3.4 Infliximab Data on patients with AS treated with infliximab were obtained from six PC studies, all fulllength articles [54, 55, 62, 113-115]. Some studies reported significant increases in TC [54, 62], HDL-C [54, 62], and TG [54], whereas Ersozlu Bozkirli et al. [113] reported no significant changes in these lipids. There was no significant change in LDL-C [54, 62, 113] or AIx [115]. There was significant reduction in CRP $[55,62,113,115]$ and the Framingham 10-year CV risk [113]. The results were mixed for atherogenic index and BP; Spanakis et al. [62] and Ersozlu Bozkirli et al. [113] reported significant decrease in atherogenic index and $\mathrm{BP}$, respectively, but others reported no significant changes in these parameters [54, 55, 115]. CV-related AEs reported included palpitations (11.4\%), hypertension $(20.0 \%)$, chest pain $(2.9 \%)$, and premature ventricular contraction $(2.9 \%)$, all of which were short-term [114]. There were no long-term CV-related AEs reported.

3.5.3.5 Secukinumab The clinical trial evaluating the effect of secukinumab on patients with AS [108, 109] reported that the exposure-adjusted incidence rate for major cardiac AEs was 0.4 per $100 \mathrm{PY}$. No other CV events were reported.

\subsection{Risk in Juvenile Idiopathic Arthritis}

\subsubsection{Study Characteristics}

The characteristics of all the studies classified by type for all therapeutic agents are given in Electronic Supplementary Material \#2 Table 7. There were a total of two RCTs (including a long-term extension) [116-119], one PC study [120], and two RC studies [41, 121] on CV risk in JIA. The number of patients enrolled in these studies ranged from 30 to 23,458 . Treatment duration depended on the therapeutic agent being evaluated and ranged from 6 to 624 weeks.

\subsubsection{Patient Characteristics}

The characteristics of all JIA patients enrolled in these studies for all therapeutic agents evaluated are summarized in Electronic Supplementary Material \#2 Table 8. Briefly, the mean age of patients enrolled in these studies ranged from 6.9 to 13.1 years, the proportion of female patients
Table 4 Summary of cardiovascular risk assessment for patients with juvenile idiopathic arthritis

\begin{tabular}{llll}
\hline Risk factor & \multicolumn{2}{l}{ boDMARD } & \\
\cline { 2 - 4 } & ADA & ETN & TCZ \\
\hline TC & & $\downarrow$ & $\leftrightarrow$ \\
HDL-C & $\leftrightarrow$ & \\
LDL-C & & $\downarrow$ & $\uparrow$ \\
TG & & $\downarrow$ & \\
Atherogenic index & & $\leftrightarrow$ & \\
CRP & & $\downarrow$ & $\downarrow$ \\
CHF & None & & \\
\hline
\end{tabular}

Blank cells indicate that data were not reported in original publications

$A D A$ adalimumab, boDMARD biological originator disease-modifying anti-rheumatic drug, $C H F$ congestive heart failure, $C R P$ C-reactive protein, $E T N$ etanercept, $H D L-C$ high-density lipoprotein cholesterol, $L D L-C$ low-density lipoprotein cholesterol, $T C$ total cholesterol, $T C Z$ tocilizumab, $T G$ triglycerides, $\uparrow$ significantly increased, $\downarrow$ significantly decreased, $\leftrightarrow$ no significant effect

ranged from 71.0 to $86.0 \%$, and the disease duration ranged from 2.5 to 4.7 years.

\subsubsection{Risk Analysis}

The results of $\mathrm{CV}$ risk analysis for all therapeutic agents are summarized in Table 4. There were no studies reporting CV events or biomarkers for patients with JIA treated with abatacept, certolizumab pegol, golimumab, infliximab, rituximab, secukinumab, tofacitinib, or ustekinumab.

3.6.3.1 Adalimumab The single RC study evaluating the effect of adalimumab in patients with JIA reported no $\mathrm{CHF}$ events [41].

3.6.3.2 Etanercept Data on patients with JIA treated with etanercept were obtained from one PC study (full-length article) [120] and one RC study (conference abstract) [121]. Among children with JIA, treatment with etanercept significantly decreased TC, LDL-C, TG, and CRP, but not HDL-C [120]. However, this overall improvement in lipid profile and inflammation did not translate into improvement in atherogenic index. Among adult patients with JIA who received etanercept during childhood, the prevalence of CVD was $10.8 \%$ [121], which was similar to that observed in the general population. However, patients with systemic JIA had a significantly higher rate of CVD.

3.6.3.3 Tocilizumab In the CHERISH trial [116, 117], treatment with tocilizumab resulted in 34.6 and $11.4 \%$ of patients having TC levels $\geq 170 \mathrm{mg} / \mathrm{dL}$ and LDL-C 
levels $\geq 110 \mathrm{mg} / \mathrm{dL}$, respectively. Levels of cholesterol exceeding the upper limit of normal for TC or LDL-C were observed at least once in $31 \%$ of the patients who received tocilizumab. In the TENDER trial [118], patients with JIA and insulin resistance treated with tocilizumab showed significant reductions in HOMA-IR at week 6, which was associated with improvement in Juvenile Arthritis Disease Activity Score and active joint count. In the long-term extension study [119] there was no change in mean TC, but $11.9 \%$ of patients reported grade 2 elevation.

\section{Discussion}

This systematic literature search for the effect of bDMARDs and tsDMARDs on CV events among patients with rheumatic diseases resulted in 105 publications from 95 separate studies. The risk of bias analyses demonstrated that the methodological rigor of the studies included in this review was fairly high, indicating that information obtained from these reports was reliable.

Of the 95 studies, 73 (76.8\%) included patients with RA, seven (7.4\%) included patients with PsA, 11 (11.6\%) included patients with AS, and five (5.3\%) included patients with JIA; the total is greater than $100 \%$ as some studies included multiple indications. The information available was heavily skewed towards CV effects in patients with RA, with some data published on ten of the 11 therapeutic agents being evaluated. By comparison, information was available from only five therapeutic agents each for patients with PsA and AS, and three therapeutic agents for patients with JIA. Sufficient relevant data were available for only etanercept for all four rheumatic diseases being evaluated; although data for adalimumab were available for all four diseases, the information was primarily for RA with scant information on the other three diseases. Data for infliximab were available for RA, PsA, and AS. Data on the other eight therapeutic agents were essentially limited to one disease: seven for RA and one (golimumab) for AS. Furthermore, not all studies reported the same parameters. Thus, the patchwork of data available poses a challenge when comparing therapeutic agents across diseases and derive definitive conclusions regarding their effects.

Although the overall effects on the lipid profiles were mixed, some patterns were discernible. Six of the therapeutic agents (etanercept, golimumab, infliximab, rituximab, tocilizumab, and tofacitinib) caused significant increase in TC, with an additional three (abatacept, adalimumab, and secukinumab) indicating no change; significant decrease was only reported in patients with JIA treated with etanercept. Significant increase in HDL-C was reported for eight (abatacept, adalimumab, etanercept, golimumab, infliximab, rituximab, tocilizumab, and tofacitinib) of the therapeutic agents regardless of disease; only secukinumab did not increase HDL-C and no data were reported for certolizumab pegol or ustekinumab. The results with LDL-C, TG, and atherogenic index were mixed depending on the study/investigators, with about an equal number reporting significant increase or no change; significant decrease was only reported in patients with JIA treated with etanercept. The ApoB:ApoA-1 ratio was significantly decreased only in patients with RA and AS treated with etanercept; there was no effect on patients with RA treated with adalimumab or secukinumab or patients with PsA treated with etanercept. The apparent increase in HR for CVD among patients with RA treated with biologics seemed counterintuitive. Further examination of the publications revealed that these HRs were determined relative to a comparator biologic or nbDMARD and the $95 \%$ confidence intervals included 1 . Thus, these values do not indicate the real HRs of these drugs versus placebo. Consequently, it cannot be concluded that there was an increase in $\mathrm{CV}$ risk when treated with biologics.

Consistently, CRP was significantly decreased across eight of the therapeutic agents (there were no data for certolizumab pegol, secukinumab, or ustekinumab) and diseases. The data for surrogate markers were mixed. When reported, there was significant decrease in CAVI (adalimumab, etanercept, and tocilizumab, but not abatacept) and AIx (adalimumab, etanercept and tocilizumab, but not abatacept, golimumab, or rituximab; there was either no change or increase in response to infliximab treatment). There was generally no significant effect on cIMT or BP.

\subsection{Limitations}

The main limitation of this review is the variability in reporting of CVD events and CV risk factors in the publications identified. This has resulted in many gaps in data, making it difficult for direct comparison between drugs within the same disease. Furthermore, the same risk factors and $\mathrm{CV}$ events were not reported for a given drug across all four rheumatic diseases, making it difficult to evaluate whether or not there was a consistent pattern of response that could be attributed to that drug. In some cases, the only data available were from a published conference abstract or a single study, adding to the difficulty of this analysis. Thus, the conclusions drawn from this analysis need to be interpreted with caution.

\section{Conclusions}

There were no reports of significant increases in rates of $\mathrm{CV}$ outcomes when treated with these drugs. The data analyzed and reported in this paper indicate treatment with 
bDMARDs or tsDMARDs do not appear to be associated with adverse $\mathrm{CV}$ outcomes.

Acknowledgements Editorial/medical writing support was provided by Mukund Nori, PhD, MBA, CMPP, of Engage Scientific Solutions and was funded by Pfizer. Sadiq Lula was an employee of Envision Pharma Group at the time the work was done. Carole Jones of Envision Pharma Group was involved with the development of the systematic literature review, which was funded by Pfizer.

\section{Compliance with Ethical Standards}

Funding The systematic literature review to support the manuscript and medical writing assistance were sponsored by Pfizer.

Conflict of interest Dr. Michael Nurmohamed has received grants, consulting fees, support for travel to meetings, and speaker bureau fees from AbbVie, BMS, Celgene, Eli Lilly, Janssen, Menarini, MSD, Mundipharma, Pfizer, Roche, Sanofi, and UCB; fees for participating in review activities from AbbVie; and provision of writing assistance from Pfizer. Dr Ernest Choy has received grants from Novimmune, Pfizer, Roche, and UCB; consulting fees from Abbott Laboratories, Amgen, Biogen, BMS, Celgene, Chugai Pharma, Eli Lilly, GSK, Hospira, Janssen, MedImmune, Napp, Novimmune, Novartis, Pfizer, Regeneron, Roche, R-Pharm, and Sanofi-Aventis; fees for participating in review activities from AB2 Bio Ltd; speaker bureau fees from Amgen, BMS, Boehringer Ingelheim, Chugai Pharma, Eli Lilly, Hospira, MSD, Novartis, Pfizer, Regeneron, Roche, Sanofi-Aventis, and UCB. Mr Sadiq Lula was an employee of Envision Pharma Group, which was paid by Pfizer to perform the systematic literature review. Drs Blerina Kola, Ryan DeMasi, and Paola Accossato are employees of Pfizer and own stock in the company.

Open Access This article is distributed under the terms of the Creative Commons Attribution-NonCommercial 4.0 International License (http://creativecommons.org/licenses/by-nc/4.0/), which permits any noncommercial use, distribution, and reproduction in any medium, provided you give appropriate credit to the original author(s) and the source, provide a link to the Creative Commons license, and indicate if changes were made.

\section{References}

1. Al Maini M, Adelowo F, Al Saleh J, Al Weshahi Y, Burmester GR, Cutolo M, et al. The global challenges and opportunities in the practice of rheumatology: white paper by the World Forum on Rheumatic and Musculoskeletal Diseases. Clin Rheumatol. 2015;34(5):819-29.

2. Avina-Zubieta JA, Thomas J, Sadatsafavi M, Lehman AJ, Lacaille D. Risk of incident cardiovascular events in patients with rheumatoid arthritis: a meta-analysis of observational studies. Ann Rheum Dis. 2012;71(9):1524-9.

3. Nurmohamed MT, Heslinga M, Kitas GD. Cardiovascular comorbidity in rheumatic diseases. Nat Rev Rheumatol. 2015;11(12):693-704.

4. Han C, Robinson DW Jr, Hackett MV, Paramore LC, Fraeman $\mathrm{KH}$, Bala MV. Cardiovascular disease and risk factors in patients with rheumatoid arthritis, psoriatic arthritis, and ankylosing spondylitis. J Rheumatol. 2006;33(11):2167-72.

5. Husted JA, Thavaneswaran A, Chandran V, Eder L, Rosen CF, Cook RJ, et al. Cardiovascular and other comorbidities in patients with psoriatic arthritis: a comparison with patients with psoriasis. Arthritis Care Res (Hoboken). 2011;63(12):1729-35.

6. Lim DT, Cannella AC, Michaud KD, Mikuls TR. Cardiovascular risk and the use of biologic agents in rheumatoid arthritis. Curr Rheumatol Rep. 2014;16(11):459.

7. Westlake SL, Colebatch AN, Baird J, Curzen N, Kiely P, Quinn $\mathrm{M}$, et al. Tumour necrosis factor antagonists and the risk of cardiovascular disease in patients with rheumatoid arthritis: a systematic literature review. Rheumatology (Oxford). 2011;50(3):518-31.

8. Zhang J, Chen L, Delzell E, Muntner P, Hillegass WB, Safford $\mathrm{MM}$, et al. The association between inflammatory markers, serum lipids and the risk of cardiovascular events in patients with rheumatoid arthritis. Ann Rheum Dis. 2014;73(7):1301-8.

9. Schieir O, Tosevski C, Glazier RH, Hogg-Johnson S, Badley EM. Incident myocardial infarction associated with major types of arthritis in the general population: a systematic review and meta-analysis. Ann Rheum Dis. 2017;76(8):1396-404.

10. Singh JA, Saag KG, Bridges SL Jr, Akl EA, Bannuru RR, Sullivan MC, et al. 2015 American College of Rheumatology guideline for the treatment of rheumatoid arthritis. Arthritis Rheumatol. 2016;68(1):1-26.

11. Smolen JS, Landewe R, Breedveld FC, Buch M, Burmester G, Dougados M, et al. EULAR recommendations for the management of rheumatoid arthritis with synthetic and biological disease-modifying antirheumatic drugs: 2013 update. Ann Rheum Dis. 2014;73(3):492-509.

12. Moher D, Liberati A, Tetzlaff J, Altman DG. Preferred reporting items for systematic reviews and meta-analyses: the PRISMA statement. BMJ. 2009;339:b2535.

13. Berger VW, Alperson SY. A general framework for the evaluation of clinical trial quality. Rev Recent Clin Trials. 2009;4(2):79-88.

14. Downs SH, Black N. The feasibility of creating a checklist for the assessment of the methodological quality both of randomised and non-randomised studies of health care interventions. J Epidemiol Community Health. 1998;52(6):377-84.

15. Trac MH, McArthur E, Jandoc R, Dixon SN, Nash DM, Hackam DG, et al. Macrolide antibiotics and the risk of ventricular arrhythmia in older adults. CMAJ. 2016;188(7):E120-9.

16. Kume K, Amano K, Yamada S, Ohta H. Tocilizumab improves arterial stiffness compared with abatacept in patients with TNF blockers resistant active rheumatoid arthritis. An open label randomized controlled trial [abstract]. Arthritis Rheum. 2011;63:395.

17. Provan SA, Berg IJ, Hammer HB, Mathiessen A, Kvien TK, Semb AG. The impact of newer biological disease modifying anti-rheumatic drugs on cardiovascular risk factors: a 12-month longitudinal study in rheumatoid arthritis patients treated with rituximab, abatacept and tociliziumab. PLoS One. 2015;10(6): 0130709.

18. Kume K, Amano K, Yamada S, et al. Abatacept does not improve subclinical atherosclerosis despite good response in rheumatoid arthritis: a cohort study [abstract]. Arthritis Rheum. 2015;67(Suppl 10):547.

19. Johnson S, Turpcu A, Shi N, Moawad D, Alexamder K. Risk of cardiovascular events in rheumatoid arthritis patients treated with subsequent line biologic disease modifying antirheumatic drugs after switching from first line anti tumor necrosis factor agents [abstract]. Arthritis Rheum. 2011;63:113.

20. Curtis JR, Jeffrey R, Yun H, Zhang J, Hie F, Chen L, et al. Comparing myocardial infarction risks associated with biologics of varying mechanisms of action among older rheumatoid arthritis patients [abstract]. Arthritis Rheum. 2013;65:363.

21. Harrold L, John A, Reed G, Reiss W, Magner R, Chung C, et al. The use and effectiveness of rituximab in patients with 
rheumatoid arthritis observational study: Corrona registry [abstract]. Ann Rheum Dis. 2013;71(Suppl 3):669.

22. Khraishi M, Aslanov R, Doyle K. 18-Month cardiovascular risk assessment in rheumatoid arthritis (RA) patients treated by biologic response modifiers [abstract]. Ann Rheum Dis. 2013;72(Suppl 3):A598.

23. Pappas DA, John A, Kremer J, Reed G, Greenberg J, Shewade A, et al. Effect of biologic agents on lipids and cardiovascular risk in rheumatoid arthritis patients [abstract]. Ann Rheum Dis. 2013;72(Suppl 3):A49.

24. Saito K, Hanami K, Hirata S, Kubo S, Nawata M, Yamaoka K, et al. Comparison of lipid profile including high molecular weight adiponectin (HMW-AN) after treatment with three different biologics in the patients with bio-naïve rheumatoid arthritis (RA) [abstract]. Ann Rheum Dis. 2013;72(Suppl 3):A459-A.

25. Harrold L, John A, Reed G, Karki C, Li YF, Kremer J, et al. Impact of tocilizumab monotherapy in patients with moderate to high disease activity: Real-world analyses from the US CORRONA Registry [abstract]. Arthritis Rheum. 2015;67:2771.

26. Gabay C, Emery P, van Vollenhoven R, Dikranian A, Alten R, Pavelka K, et al. Tocilizumab monotherapy versus adalimumab monotherapy for treatment of rheumatoid arthritis (ADACTA): a randomised, double-blind, controlled phase 4 trial. Lancet. 2013;381(9877):1541-50.

27. Kume K, Amano K, Yamada S, Hatta K, Ohta H, Kuwaba N. Tocilizumab monotherapy reduces arterial stiffness as effectively as etanercept or adalimumab monotherapy in rheumatoid arthritis: an open-label randomized controlled trial. J Rheumatol. 2011;38(10):2169-71.

28. van Vollenhoven RF, Emery P, Bingham CO 3rd, Keystone EC, Fleischmann RM, Furst DE, et al. Long-term safety of rituximab in rheumatoid arthritis: 9.5-year follow-up of the global clinical trial programme with a focus on adverse events of interest in RA patients. Ann Rheum Dis. 2013;72(9):1496-502.

29. van Vollenhoven RF, Fleischmann R, Cohen S, Lee EB, García Meijide JA, Wagner S, et al. Tofacitinib or adalimumab versus placebo in rheumatoid arthritis. $\mathrm{N}$ Engl $\mathrm{J}$ Med. 2012;367(6):508-19.

30. Kume K, Amano K, Yamada S, Ohta H. Tocilizumab monotherapy improves arterial stiffness compared with other biologics monotherapy in rheumatoid arthritis [abstract]. Arthritis Rheum. 2010;62:1839.

31. van Vollenhoven R, Emery P, Bingham CO, Keystone E, Fleischmann R, Furst D, et al. Long-term safety of rituximab: 10-year follow-up in the rheumatoid arthritis global clinical trial program [abstract]. Ann Rheum Dis. 2012;71(Suppl 3):195.

32. Gabay C, Tuckwell K, Green J, Klearman M, Kavanaugh A. Tocilizumab monotherapy compared with adalimumab monotherapy in patients with rheumatoid arthritis: an evaluation of high-density lipoprotein composition [abstract]. Arthritis Rheum. 2013;65:450.

33. Wijbrandts CA, van Leuven SI, Boom HD, Gerlag DM, Stroes EG, Kastelein JJ, et al. Sustained changes in lipid profile and macrophage migration inhibitory factor levels after anti-tumour necrosis factor therapy in rheumatoid arthritis. Ann Rheum Dis. 2009;68(8):1316-21.

34. Peters MJ, Welsh P, McInnes IB, Wolbink G, Dijkmans BA, Sattar N, et al. Tumour necrosis factor alpha blockade reduces circulating $\mathrm{N}$-terminal pro-brain natriuretic peptide levels in patients with active rheumatoid arthritis: results from a prospective cohort study. Ann Rheum Dis. 2010;69(7):1281-5.

35. Davies R, Galloway JB, Watson KD, Lunt M, Symmons DP, Hyrich KL. Venous thrombotic events are not increased in patients with rheumatoid arthritis treated with anti-TNF therapy: results from the British Society for Rheumatology Biologics Register. Ann Rheum Dis. 2011;70(10):1831-4.

36. Gonzalez-Juanatey C, Vazquez-Rodriguez TR, Miranda-Filloy JA, Gomez-Acebo I, Testa A, Garcia-Porrua C, et al. Anti-TNFalpha-adalimumab therapy is associated with persistent improvement of endothelial function without progression of carotid intima-media wall thickness in patients with rheumatoid arthritis refractory to conventional therapy. Mediators Inflamm. 2012;2012:674265.

37. Ormseth MJ, Yancey PG, Solus JF, Bridges SL, Curtis JR, Linton MF, et al. Effect of drug therapy on net cholesterol efflux capacity of HDL-enriched serum in rheumatoid arthritis [abstract]. Arthritis Rheumatol. 2015;67:1553.

38. Marchesoni A, Zaccara E, Gorla R, Bazzani C, Sarzi-Puttini P, Atzeni F, et al. TNF-alpha antagonist survival rate in a cohort of rheumatoid arthritis patients observed under conditions of standard clinical practice. Ann N Y Acad Sci. 2009;1173:837-46.

39. Korswagen LA, Bartelds GM, Krieckaert CL, Turkstra F, Nurmohamed MT, van Schaardenburg D, et al. Venous and arterial thromboembolic events in adalimumab-treated patients with antiadalimumab antibodies: a case series and cohort study. Arthritis Rheum. 2011;63(4):877-83.

40. Ronda N, Greco D, Adorni MP, Zimetti F, Favari E, Hjeltnes G, et al. Newly identified antiatherosclerotic activity of methotrexate and adalimumab: complementary effects on lipoprotein function and macrophage cholesterol metabolism. Arthritis Rheumatol. 2015;67(5):1155-64.

41. Burmester GR, Panaccione R, Gordon KB, McIlraith MJ, Lacerda AP. Adalimumab: long-term safety in 23458 patients from global clinical trials in rheumatoid arthritis, juvenile idiopathic arthritis, ankylosing spondylitis, psoriatic arthritis, psoriasis and Crohn's disease. Ann Rheum Dis. 2013;72(4):517-24.

42. Keystone E, Heijde D, Mason D Jr, Landewe R, Vollenhoven $\mathrm{RV}$, Combe B, et al. Certolizumab pegol plus methotrexate is significantly more effective than placebo plus methotrexate in active rheumatoid arthritis: findings of a fifty-two-week, phase III, multicenter, randomized, double-blind, placebo-controlled, parallel-group study. Arthritis Rheum. 2008;58(11):3319-29.

43. Keystone EC, Combe B, Smolen J, Strand V, Goel N, van Vollenhoven R, et al. Sustained efficacy of certolizumab pegol added to methotrexate in the treatment of rheumatoid arthritis: 2-year results from the RAPID 1 trial. Rheumatology (Oxford). 2012;51(9):1628-38.

44. Weisman MH, Paulus HE, Burch FX, Kivitz AJ, Fierer J, Dunn $\mathrm{M}$, et al. A placebo-controlled, randomized, double-blinded study evaluating the safety of etanercept in patients with rheumatoid arthritis and concomitant comorbid diseases. Rheumatology (Oxford). 2007;46(7):1122-5.

45. Daien CI, Fesler P, du Cailar G, Daien V, Mura T, Dupuy AM, et al. Etanercept normalises left ventricular mass in patients with rheumatoid arthritis. Ann Rheum Dis. 2013;72(6):881-7.

46. Galarraga B, Khan F, Kumar P, Pullar T, Belch JJ. Etanercept improves inflammation-associated arterial stiffness in rheumatoid arthritis. Rheumatology (Oxford). 2009;48(11):1418-23.

47. Jamnitski A, Visman IM, Peters MJ, Dijkmans BA, Voskuyl AE, Nurmohamed MT. Beneficial effect of 1-year etanercept treatment on the lipid profile in responding patients with rheumatoid arthritis: the ETRA study. Ann Rheum Dis. 2010;69(11):1929-33.

48. Rodriguez-Jimenez NA, Garcia-Gonzalez CE, Ayala-Lopez KP, Trujillo-Hernandez B, Aguilar-Chavez EA, Rocha-Munoz AD, et al. Modifications in lipid levels are independent of serum TNF-alpha in rheumatoid arthritis: results of an observational 24-week cohort study comparing patients receiving etanercept 
plus methotrexate or methotrexate as monotherapy. Biomed Res Int. 2014;2014:510305.

49. Curtis JR, Kramer JM, Martin C, Saag KG, Patkar N, Shatin D, et al. Heart failure among younger rheumatoid arthritis and Crohn's patients exposed to TNF-alpha antagonists. Rheumatology (Oxford). 2007;46(11):1688-93.

50. Morgan CL, Emery P, Porter D, Reynolds A, Young A, Boyd H, et al. Treatment of rheumatoid arthritis with etanercept with reference to disease-modifying anti-rheumatic drugs: long-term safety and survival using prospective, observational data. Rheumatology (Oxford). 2014;53(1):186-94.

51. Wolfe F, Michaud K. Heart failure in rheumatoid arthritis: rates, predictors, and the effect of anti-tumor necrosis factor therapy. Am J Med. 2004;116(5):305-11.

52. Poole C, Emery P, Young A, Porter D, Morgan C, Walker H, et al. Safety and efficacy of etanercept over five years in a large, UK observational cohort [abstract]. Arthritis Rheum. 2011;63:S481-2.

53. Bathon J, Wasko M, Kirkham B, Touboul P, Hsia E, Xu W, et al. Golimumab and cardiovascular disease: Carotid artery ultrasound evaluation and cardiovascular adverse events [abstract]. Arthritis Rheum. 2010;62:386.

54. Kiortsis DN, Mavridis AK, Filippatos TD, Vasakos S, Nikas SN, Drosos AA. Effects of infliximab treatment on lipoprotein profile in patients with rheumatoid arthritis and ankylosing spondylitis. J Rheumatol. 2006;33(5):921-3.

55. Pieringer H, Stuby U, Pohanka E, Biesenbach G. Augmentation index in patients with rheumatoid arthritis and ankylosing spondylitis treated with infliximab. Clin Rheumatol. 2010;29(7):723-7.

56. Tam LS, Shang Q, Li EK, Wang S, Li RJ, Lee KL, et al. Infliximab is associated with improvement in arterial stiffness in patients with early rheumatoid arthritis - a randomized trial. J Rheumatol. 2012;39(12):2267-75.

57. Bissell L, Hensor E, Mackie S, Burska A, Nam J, Kozera L, et al. Improvement in insulin resistance greater with the use of infliximab following intensive treatment of early rheumatoid arthritis [abstract]. Arthritis Rheum. 2013;65:2766.

58. Bissell L, Mackie S, Kozera L, Nam J, Burska A, Hensor E, et al. Improvement in some, but not all, surrogate measures of cardiovascular disease following intensive treatment of early rheumatoid arthritis [abstract]. Ann Rheum Dis. 2013;71:350.

59. Vis M, Nurmohamed MT, Wolbink G, Voskuyl AE, de Koning $M$, van de Stadt R, et al. Short term effects of infliximab on the lipid profile in patients with rheumatoid arthritis. J Rheumatol. 2005;32(2):252-5.

60. Allanore Y, Kahan A, Sellam J, Ekindjian OG, Borderie D. Effects of repeated infliximab therapy on serum lipid profile in patients with refractory rheumatoid arthritis. Clin Chim Acta. 2006;365(1-2):143-8.

61. Dahlqvist SR, Engstrand S, Berglin E, Johnson O. Conversion towards an atherogenic lipid profile in rheumatoid arthritis patients during long-term infliximab therapy. Scand J Rheumatol. 2006;35(2):107-11.

62. Spanakis E, Sidiropoulos P, Papadakis J, Ganotakis E, Katsikas G, Karvounaris S, et al. Modest but sustained increase of serum high density lipoprotein cholesterol levels in patients with inflammatory arthritides treated with infliximab. J Rheumatol. 2006;33(12):2440-6.

63. Peters MJ, Vis M, van Halm VP, Wolbink GJ, Voskuyl AE, Lems WF, et al. Changes in lipid profile during infliximab and corticosteroid treatment in rheumatoid arthritis. Ann Rheum Dis. 2007;66(7):958-61.

64. Nishida K, Okada Y, Nawata M, Saito K, Tanaka Y. Induction of hyperadiponectinemia following long-term treatment of patients with rheumatoid arthritis with infliximab (IFX), an antiTNF-alpha antibody. Endocr J. 2008;55(1):213-6.

65. Popa C, van Tits LJ, Barrera P, Lemmers HL, van den Hoogen $\mathrm{FH}$, van Riel PL, et al. Anti-inflammatory therapy with tumour necrosis factor alpha inhibitors improves high-density lipoprotein cholesterol antioxidative capacity in rheumatoid arthritis patients. Ann Rheum Dis. 2009;68(6):868-72.

66. Delabaye I, De Keyser F. 74-week follow-up of safety of infliximab in patients with refractory rheumatoid arthritis. Arthritis Res Ther. 2010;12(3):R121.

67. Cetin S, Mustafa G, Keskin G, Yeter E, Doğan M, Öztürk MA. Infliximab, an anti-TNF-alpha agent, improves left atrial abnormalities in patients with rheumatoid arthritis: preliminary results. Cardiovasc J Afr. 2014;25(4):168-75.

68. Ayyildiz YO, Vural MG, Efe TH, Ertem AG, Koseoglu C, Ayturk M, et al. Effect of long-term TNF-alpha inhibition with infliximab on left ventricular torsion in patients with rheumatoid arthritis. Hellenic J Cardiol. 2015;56(5):406-13.

69. Vural M, Ay B, Cagirci G, Akdemir R, Keskin G, Yeter E. Chronic inhibition of tumor necrosis factor alpha with infliximab improves myocardial deformation in parallel with aortic elasticity in rheumatoid arthritis [abstract]. Eur Heart J. 2013;34(suppl 1):P3830.

70. Saiki O, Takao R, Naruse Y, Kuhara M, Imai S, Uda H. Infliximab but not methotrexate induces extra-high levels of VLDL-triglyceride in patients with rheumatoid arthritis. J Rheumatol. 2007;34(10):1997-2004.

71. Mathieu S, Pereira B, Dubost JJ, Lusson JR, Soubrier M. No significant change in arterial stiffness in RA after 6 months and 1 year of rituximab treatment. Rheumatology (Oxford). 2012;51(6):1107-11.

72. Patschan S, Nemirovsky K, Henze E, Scholze J, Muller GA, Patschan D. Tocilizumab increases EPC regeneration in rheumatoid arthritis. Scand J Rheumatol. 2014;43(6):528-30.

73. Raterman HG, Levels H, Voskuyl AE, Lems WF, Dijkmans BA, Nurmohamed MT. HDL protein composition alters from proatherogenic into less atherogenic and proinflammatory in rheumatoid arthritis patients responding to rituximab. Ann Rheum Dis. 2013;72(4):560-5.

74. Novikova D, Popkova T, Gerasimova E, Markelova E, Volkov A, Fomicheva O, et al. Favorable effects of rituximab treatment on lipid profile, arterial stiffness, carotid atherosclerosis and silent myocardial ischemia in women with rheumatoid arthritis [abstract]. Ann Rheum Dis. 2014;73(Suppl 2):496.

75. Saag KG, Winthrop KL, Alexander K, Francom S, Furst DE. Long-term targeted safety event rates in RA patients following initiation of rituximab: interim analysis from SUNSTONE registry [abstract]. Arthritis Rheum. 2013;65:S1002.

76. van Vollenhoven RF, Fleischmann RM, Furst DE, Lacey S, Lehane PB. Longterm Safety of Rituximab: Final Report of the Rheumatoid Arthritis Global Clinical Trial Program over 11 Years. J Rheumatol. 2015;42(10):1761-6.

77. Durez P, Genovese M, Kellner H, Codding C, Ligozio G, Richards $\mathrm{H}$, et al. Lack of effect of secukinumab treatment on the lipid profile in patients with rheumatoid arthritis: Results from a randomized, double-blind, placebo-controlled, phase II study [abstract]. Ann Rheum Dis. 2013;71:194-5.

78. Kellner H, Durez P, Genovese M, Codding C, Ligozio G, Richards $\mathrm{H}$, et al. Unaltered lipid profile in patients with rheumatoid arthritis receiving secukinumab: Results from a randomized, double-blind, placebo-controlled, phase II study [abstract]. Zeitschrift für Rheumatologie. 2012;71(Suppl 2):99.

79. Maini RN, Taylor PC, Szechinski J, Pavelka K, Broll J, Balint $\mathrm{G}$, et al. Double-blind randomized controlled clinical trial of the interleukin-6 receptor antagonist, tocilizumab, in European patients with rheumatoid arthritis who had an incomplete 
response to methotrexate. Arthritis Rheum. 2006;54(9):2817-29.

80. Genovese MC, McKay JD, Nasonov EL, Mysler EF, da Silva NA, Alecock E, et al. Interleukin-6 receptor inhibition with tocilizumab reduces disease activity in rheumatoid arthritis with inadequate response to disease-modifying antirheumatic drugs: the tocilizumab in combination with traditional disease-modifying antirheumatic drug therapy study. Arthritis Rheum. 2008;58(10):2968-80.

81. Jones G, Sebba A, Gu J, Lowenstein MB, Calvo A, GomezReino JJ, et al. Comparison of tocilizumab monotherapy versus methotrexate monotherapy in patients with moderate to severe rheumatoid arthritis: the AMBITION study. Ann Rheum Dis. 2010;69(1):88-96.

82. Fleischmann RM, Halland AM, Brzosko M, Burgos-Vargas R, Mela C, Vernon E, et al. Tocilizumab inhibits structural joint damage and improves physical function in patients with rheumatoid arthritis and inadequate responses to methotrexate: LITHE study 2-year results. J Rheumatol. 2013;40(2):113-26.

83. McInnes IB, Kim HY, Lee SH, Mandel D, Song YW, Connell $\mathrm{CA}$, et al. Open-label tofacitinib and double-blind atorvastatin in rheumatoid arthritis patients: a randomised study. Ann Rheum Dis. 2014;73(1):124-31.

84. Mirjafari H, Wang J, Klearman M, Harari O, Bruce I. Insulin resistance is improved by tocilizumab therapy in rheumatoid arthritis: Results from the TOWARD study [abstract]. Ann Rheum Dis. 2013;72:A414-5.

85. Herold M, Fasching P, Graininger W, Lunzer R, Zamani O, Leeb B. Increased serum lipids under tocilizumab is not influenced by methotrexate [abstract]. Arthritis Rheumatol. 2015;67:496.

86. Koike T, Harigai M, Inokuma S, Ishiguro N, Ryu J, Takeuchi T, et al. Postmarketing surveillance of tocilizumab for rheumatoid arthritis in Japan: interim analysis of 3881 patients. Ann Rheum Dis. 2011;70(12):2148-51.

87. Curtis JR, Perez-Gutthann S, Suissa S, Napalkov P, Singh N, Thompson L, et al. Tocilizumab in rheumatoid arthritis: a case study of safety evaluations of a large postmarketing data set from multiple data sources. Semin Arthritis Rheum. 2015;44(4):381-8.

88. Yamamoto K, Goto H, Hirao K, Nakajima A, Origasa H, Tanaka $\mathrm{K}$, et al. Longterm safety of tocilizumab: results from 3 years of followup postmarketing surveillance of 5573 patients with rheumatoid arthritis in Japan. J Rheumatol. 2015;42(8):1368-75.

89. Kume K, Amano K, Yamada S, et al. Tocilizumab improves left ventricular mass and cardiac output in patients with rheumatoid arthritis. A cohort study [poster]. Arthritis Rheum. 2013;65:1410.

90. Yamanaka H, Tanaka Y, Inoue E, Hoshi D, Momohara S, Hanami $\mathrm{K}$, et al. Efficacy and tolerability of tocilizumab in rheumatoid arthritis patients seen in daily clinical practice in Japan: results from a retrospective study (REACTION study). Mod Rheumatol. 2011;21(2):122-33.

91. Kingston C, Benson C. Audit of trend in cholesterol levels in patients initiated on tocilizumab [abstract]. Ir J Med Sci. 2014;183:S115.

92. McInnes IB, Thompson L, Giles JT, Bathon JM, Salmon JE, Beaulieu AD, et al. Effect of interleukin-6 receptor blockade on surrogates of vascular risk in rheumatoid arthritis: MEASURE, a randomised, placebo-controlled study. Ann Rheum Dis. 2015;74(4):694-702.

93. Kremer JM, Bloom BJ, Breedveld FC, Coombs JH, Fletcher MP, Gruben D, et al. The safety and efficacy of a JAK inhibitor in patients with active rheumatoid arthritis: results of a doubleblind, placebo-controlled phase IIa trial of three dosage levels of
CP-690,550 versus placebo. Arthritis Rheum. 2009;60(7):1895-905.

94. Fleischmann R, Kremer J, Cush J, Schulze-Koops H, Connell CA, Bradley JD, et al. Placebo-controlled trial of tofacitinib monotherapy in rheumatoid arthritis. $\mathrm{N}$ Engl $\mathrm{J}$ Med. 2012;367(6):495-507.

95. Kremer JM, Cohen S, Wilkinson BE, Connell CA, French JL, Gomez-Reino J, et al. A Phase IIb dose-ranging study of the oral JAK inhibitor tofacitinib (CP-690,550) versus placebo in combination with background methotrexate in patients with active rheumatoid arthritis and an inadequate response to methotrexate alone. Arthritis Rheum. 2012;64(4):970-81.

96. Kremer J, Li ZG, Hall S, Fleischmann R, Genovese M, MartinMola E, et al. Tofacitinib in combination with nonbiologic disease-modifying antirheumatic drugs in patients with active rheumatoid arthritis: a randomized trial. Ann Intern Med. 2013;159(4):253-61.

97. Lee EB, Fleischmann R, Hall S, Wilkinson B, Bradley JD, Gruben D, et al. Tofacitinib versus methotrexate in rheumatoid arthritis. N Engl J Med. 2014;370(25):2377-86.

98. Charles-Schoeman C, Fleischmann R, Davignon J, Schwartz H, Turner SM, Beysen C, et al. Potential mechanisms leading to the abnormal lipid profile in patients with rheumatoid arthritis versus healthy volunteers and reversal by tofacitinib. Arthritis Rheumatol. 2015;67(3):616-25.

99. Tanaka Y, Takeuchi T, Yamanaka H, Nakamura H, Toyoizumi S, Zwillich S. Efficacy and safety of tofacitinib as monotherapy in Japanese patients with active rheumatoid arthritis: a 12-week, randomized, phase 2 study. Mod Rheumatol. 2015;25(4):514-21.

100. Charles-Schoeman C, Dikranian A, Taylor J, Wilkinson B, Jones T, Kwok K, et al. Assessment of lipid changes in patients with early rheumatoid arthritis treated with tofacitinib or methotrexate over 24 months [abstract]. Arthritis Rheum. 2014;66:487.

101. Fleischmann R, Lee E, Hall S, et al. Tofacitinib monotherapy versus methotrexate in methotrexate-naïve patients with rheumatoid arthritis: radiographic, clinical and functional comparison [abstract]. Arthritis Rheumatol. 2013;65:L9.

102. Kavanaugh A, Puig L, Gottlieb AB, Ritchlin CT, Li S, Wand Y, et al. Efficacy and safety of ustekinumab in patients with active psoriatic arthritis: 2-year results from a phase 3, multicenter, double-blind, placebo-controlled study [abstract]. Arthritis Rheum. 2013;65:L10.

103. Mease P, McInnes IB, Kirkham B, et al. Secukinumab provides sustained improvements in psoriatic arthritis: 2-Year efficacy and safety results from a phase 3 randomized, double-blind, placebo-controlled trial [abstract]. Arthritis Rheum. 2015;67:2148.

104. Mease PJ, McInnes IB, Kirkham B, Kavanaugh A, Rahman P, van der Heijde D, et al. Secukinumab inhibition of interleukin$17 \mathrm{a}$ in patients with psoriatic arthritis. $\mathrm{N}$ Engl $\mathrm{J}$ Med. 2015;373(14):1329-39.

105. Puig L, Strohal R, Husni ME, Tsai TF, Noppakun N, Szumski A, et al. Cardiometabolic profile, clinical features, quality of life and treatment outcomes in patients with moderate-to-severe psoriasis and psoriatic arthritis. $\mathrm{J}$ Dermatolog Treat. 2015;26(1):7-15.

106. van Dongen C, Agca R, Trivino L, Vogelzang E, Nurmohamed MT. Effect of etanercept therapy on lipid profile in patients with psoriatic arthritis [abstract]. Ann Rheum Dis. 2014;73(Suppl 2):734-5.

107. Costa L, Caso F, Atteno M, Del Puente A, Darda MA, Caso P, et al. Impact of 24-month treatment with etanercept, adalimumab, or methotrexate on metabolic syndrome components in 
a cohort of 210 psoriatic arthritis patients. Clin Rheumatol. 2014;33(6):833-9.

108. Baeten D, Blanco R, Geusens P, Sieper J, Jui-Cheng T, Martin $\mathrm{R}$, et al. Secukinumab provides sustained improvements in the signs and symptoms of active ankylosing spondylitis in antiTNF-naïve patients and those previously exposed to anti-TNF therapy: 52-week results from two randomized, double-blind, placebo-controlled phase 3 trials [abstract]. Arthritis Rheumatol. 2015;67(Suppl 10):2890.

109. Baeten D, Sieper J, Braun J, Baraliakos X, Dougados M, Emery $\mathrm{P}$, et al. Secukinumab, an interleukin-17a inhibitor, in ankylosing spondylitis. N Engl J Med. 2015;373(26):2534-48.

110. Tam LS, Shang Q, Kun EW, Lee KL, Yip ML, Li M, et al. The effects of golimumab on subclinical atherosclerosis and arterial stiffness in ankylosing spondylitis-a randomized, placebo-controlled pilot trial. Rheumatology (Oxford). 2014;53(6): 1065-74.

111. van Eijk IC, de Vries MK, Levels JH, Peters MJ, Huizer EE, Dijkmans BA, et al. Improvement of lipid profile is accompanied by atheroprotective alterations in high-density lipoprotein composition upon tumor necrosis factor blockade: a prospective cohort study in ankylosing spondylitis. Arthritis Rheum. 2009;60(5):1324-30.

112. van Halm VP, van Denderen JC, Peters MJ, Twisk JW, van der Paardt M, van der Horst-Bruinsma IE, et al. Increased disease activity is associated with a deteriorated lipid profile in patients with ankylosing spondylitis. Ann Rheum Dis. 2006;65(11):1473-7.

113. Ersozlu Bozkirli ED, Bozkirli E, Yucel AE. Effects of infliximab treatment in terms of cardiovascular risk and insulin resistance in ankylosing spondylitis patients. Mod Rheumatol. 2014;24(2):335-9.

114. Tong Q, Cai Q, de Mooij T, Xu X, Dai S, Qu W, et al. Adverse events of anti-tumor necrosis factor alpha therapy in ankylosing spondylitis. PLoS One. 2015;10(3):e0119897.
115. Yazici S, Yazici M, Erer B, Calik Y, Bulur S, Ozhan H, et al. The platelet functions in patients with ankylosing spondylitis: anti-TNF-alpha therapy decreases the mean platelet volume and platelet mass. Platelets. 2010;21(2):126-31.

116. Brunner HI, Ruperto N, Zuber Z, Keane C, Harari O, Kenwright A, et al. Efficacy and safety of tocilizumab in patients with polyarticular-course juvenile idiopathic arthritis: results from a phase 3, randomised, double-blind withdrawal trial. Ann Rheum Dis. 2015;74(6):1110-7.

117. De Benedetti F, Ruperto N, Zuber Z, Cuttica R, Keltsev V, Xavier RM, et al. Efficacy and safety of tocilizumab in patients with polyarticular juvenile idiopathic arthritis: 2-year data from the CHERISH study [abstract no. 791]. Rheumatology (Oxford). 2014;53:iii1-2.

118. Mirjafari H, Ruperto N, Brunner HI, Zuber Z, Zulian F, Maldonado-Velázquez MdR, et al. Insulin sensitivity is improved in sJIA children with insulin resistance after tocilizumab treatment: results from the TENDER study [abstract no. A54]. Arthritis Rheumatol. 2014;66(S3):S80-1.

119. Yokota S, Nozawa T, Kanetaka T, Yamazaki K, Sato T, Sakurai $\mathrm{N}$, et al. Long-term safety and effectiveness of anti-interleukin-6 receptor monoclonal antibody, tocilizumab, in patients with systemic juvenile idiopathic arthritis in Japan [abstract]. Pediatric Rheumatology. 2013;11(Suppl 2):P178.

120. De Sanctis S, Marcovecchio ML, Gaspari S, Del Torto M, Mohn A, Chiarelli F, et al. Etanercept improves lipid profile and oxidative stress measures in patients with juvenile idiopathic arthritis. J Rheumatol. 2013;40(6):943-8.

121. Raab A, Sengler C, Niewerth M, Klotsche J, Horneff G, Zink A, et al. Comorbidity profiles among adult patients with JIA who were treated with etanercept-results of the biologic register jumbo [abstract]. Ann Rheum Dis. 2013;71(Suppl 3):114. 